\title{
Performance Analysis and Improvement of Flat Torque Converters Using DOE Method
}

\author{
Guang-Qiang Wu ${ }^{1,2^{*}}$, Jie Chen ${ }^{1}$ (1) and Wen-Jie Zhu ${ }^{1}$
}

\begin{abstract}
Automotive torque converters have recently been designed with an increasingly narrower profile for the purpose of achieving a smaller axial size and reducing weight. Design of experiment (DOE) and computational fluid dynamics (CFD) techniques are applied to improve the performance of a flat torque converter. Four torque converters with different flatness ratios $(0.204,0.186,0.172$, and 0.158$)$ are designed and simulated first to investigate the effects of flatness ratio on their overall performance, including efficiency, torque ratio, and impeller torque factor. The simulation results show that the overall performance tends to deteriorate as the flatness ratio decreases. Then a parametric study covering six geometric parameters, namely, inlet and outlet angles of impeller, turbine, and stator is carried out. The results demonstrate that the inlet and outlet angles play an important role in determining the performance characteristics of a torque converter. Furthermore, the relative importance of the six design parameters is investigated using DOE method for each response (stall torque ratio and peak efficiency). The turbine outlet angle is found to exert the greatest influence on both responses. After DOE analysis, an optimized design for the flat torque converter geometry is obtained. Compared to the conventional product, the width of the optimized flat torque converter torus is reduced by about $20 \%$ while the values of stall torque ratio and peak efficiency are only decreased by $0.4 \%$ and $1.7 \%$, respectively. The proposed new optimization strategy based on DOE method together with desirability function approach can be used for performance enhancement in the design process of flat torque converters.
\end{abstract}

Keywords: Torque converter, Flatness ratio, Computational fluid dynamics (CFD), Parametric study, Design of experiment (DOE)

\section{Introduction}

Torque converters are an important part of automatic transmissions in automobiles and other vehicles. It provides automatic torque amplification according to the different rotational speed between the input and output speeds without any active control, inherently suppressing engine torque fluctuations. Because it significantly affects the fuel economy, launch feeling and drivability, interests in the development of a high efficiency and performance have been increased recently.

In recent years, with the development of computer technology, computational fluid dynamics (CFD) has been widely used in hydraulic machine design and optimization. Zhao et al. [1] optimized a double-channel

\footnotetext{
*Correspondence: wuguangqiang@tongji.edu.cn

1 School of Automotive Studies, Tongji University, Shanghai 201804, China Full list of author information is available at the end of the article
}

pump's impeller by combined using of CFD, multiobjective genetic algorithm (MOGA) and artificial neural networks (ANN). Li et al. [2] carried out an entropy production analysis to investigate the hump characteristics of a pump turbine based on CFD simulations. Shojaeefard et al. [3], Tan et al. [4] studied effects of some geometric parameters on fluid dynamic characteristics of a centrifugal pump by CFD. Many researchers have also studied the flows in torque converters by using CFD codes employing various methods $[5,6]$. Since a number of variables are involved in the design of a torque converter, it is very difficult to achieve an optimal design. In order to improve the converter performance, it is required to obtain detailed understanding and relationship between the governing parameter and its effect on the performance, including efficiency, torque ratio and impeller torque factor. Kubo et al. [7] described the relationship between the design parameters used to define 
the geometry of an automotive torque converter and the resultant efficiency in relation to the internal flow characteristics. Shin et al. $[8,9]$ investigated the effect of reactor blade geometry with varying thickness ratios, scroll angles and slot angles on the performance of a torque converter. Song et al. [10] presented an integrated design process TDOS (Torque converter Design Optimization System) including torque converter geometry designer, 3D CFD analysis module, and design optimizer. The system was used to investigate the effect of design parameters on the performance.

Most passenger cars with small and medium size engines have adopted a front-wheel-drive layout in recent years. Torque converters accordingly have been designed with an increasingly narrower profile for the purpose of achieving a smaller axial size and reducing weight. A number of researchers have studied the flat torque converter employing both analytical and experimental methods. Ejiri et al. [11] manufactured and tested four torque converters with different flatness ratios. The experimental results show that the overall performance deteriorates when the flatness ratio is reduced to less than about 0.2 . Kim et al. [12] investigated effects of the stator with two different shapes suitable for an axially squashed torus on hydraulic performance variation. Ochi et al. [13], Kietlinski et al. [14], and Usui et al. [15] developed new super-flat torque converters to provide free space for new equipments without much depreciation of efficiency. Abe et al. [16] employed newly developed stator blades to develop the fluid flow channels for a thin type torque converter with a flattening ratio of $50 \%$, while maintaining torque converter performance. Yan et al. [17] proposed a flexible flat torque converter and estimated the influence of the flatness ratio on performance. Liu et al. [18] investigated the internal flow characteristics of the flat torque converter based on elliptical design path. However, there are no reports regarding combination effect of the blade geometry including inlet and outlet angles of impeller, turbine, and stator on the flat torque converter performance characteristics.

DOE method is widely used to find the importance level of the design parameters with respect to the optimization target and obtain the best combination of design variables. Park et al. [19] studied a methane-fueled gas engine generator with addition of hydrogen using DOE method. Hatami et al. [20] applied central composite design based on DOE to obtain an optimal design of the vane geometry for a variable geometry turbine. Taghavifar et al. [21] applied DOE evaluation to introduce the optimum injection strategy-chamber geometry of diesel engine. However, there have been relatively few applications of DOE method to flat torque converters optimization.
In this paper, the main objective is to improve the overall performance of a flat torque converter by using DOE method and CFD calculations. Firstly, performance characteristics of four torque converters with different flatness ratios are investigated. Then, the sensitivity analysis is used to analyze the influence of inlet and outlet angles of impeller, turbine, and stator on the performance of a flat torque converter. Finally, the optimization analysis is performed by using DOE post-processing analysis together with desirability function approach.

\section{Flat Torque Converter Design}

\subsection{Torus Design}

The flat torque converter design started with the definition of the torus shape. A torque converter with $250 \mathrm{~mm}$ nominal diameter was chosen as the prototype model. Elliptical design method was used to redesign the mean streamline of the torque converter and flatness ratio was redefined as the rate of major axis and minor axis. The redefined flatness ratio is represented by the symbol $e$ in this paper. Given the flow area in the circular path, in the proposed torque converter model, was assumed constant, the shell and the core shapes were also redesigned. The torus design result compared with prototype model torus is shown in Figure 1.

As shown in Figure 1, the redesigned torus shows good agreement with the prototype model torus so that it could be used to design flat torque converters. Four torque converters with different flatness ratios were designed and referred to here as type 1 to type 4 , in decreasing order of flatness ratio, as shown in Table 1.

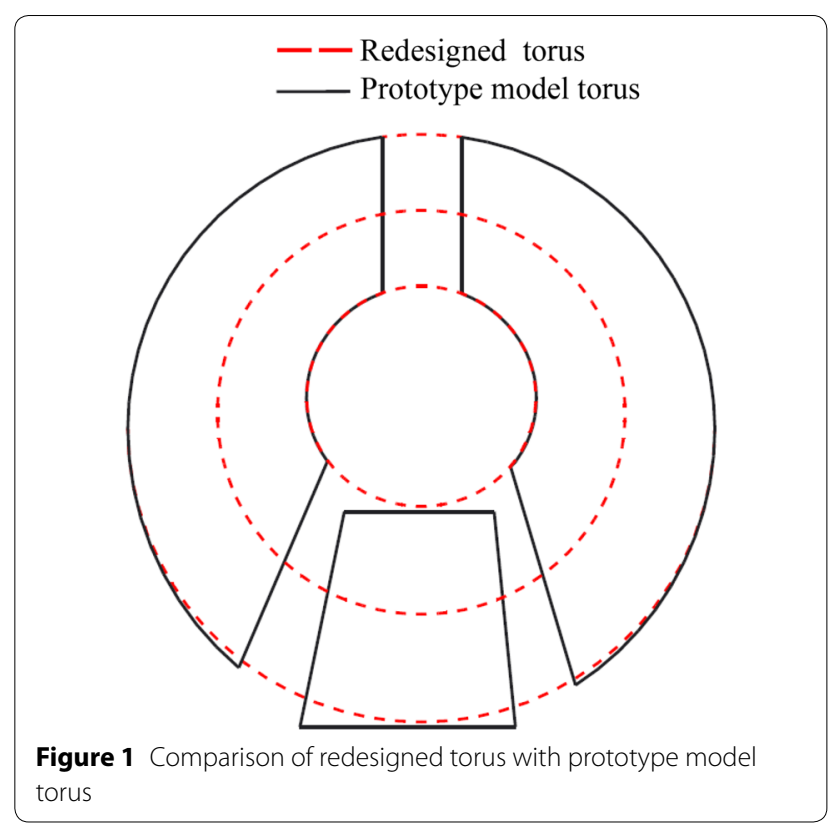


Table 1 Parameters of torus with different flatness ratios

\begin{tabular}{lllll}
\hline Parameters & Type 1 & Type 2 & Type 3 & Type 4 \\
\hline Nominal diameter $D(\mathrm{~mm})$ & 250 & 250 & 250 & 250 \\
Width of torus $W(\mathrm{~mm})$ & 51 & 46.40 & 42.95 & 39.53 \\
Flatness ratio $e_{0}$ & 0.204 & 0.186 & 0.172 & 0.158 \\
Redefined flatness ratio e & 1.0 & 0.9 & 0.8 & 0.7
\end{tabular}

Figure 2 illustrates the approach to shorten the axial dimension of the fluid flow channel. The torus could be flattened without changing the inlet radius $R_{1}$, and outlet radius $R_{2}$ of each blade element. The design parameters were unchanged as much as possible except the flatness ratio and the stator axial length was proportional to the torque converter axial length. In this present paper, four types of torus with different flatness ratio are designed using the same method.

\subsection{Blade Design}

The impeller and turbine blades were designed to match the flat torus without changing in their inlet and outlet angles on the design path, a curve that bisects the flow passage cross-sectional area. The impeller had 31 blades and the turbine had 29 blades, which all had the thickness of $1.0 \mathrm{~mm}$. The blades of four different stators all had the same distribution of thickness, it features relatively thick profile, which was better hydraulic performance than thin blades. They were also identical to each other inlet and outlet angle except for shapes. The inlet and outlet angles on the design path for the three elements are shown in Table 2.

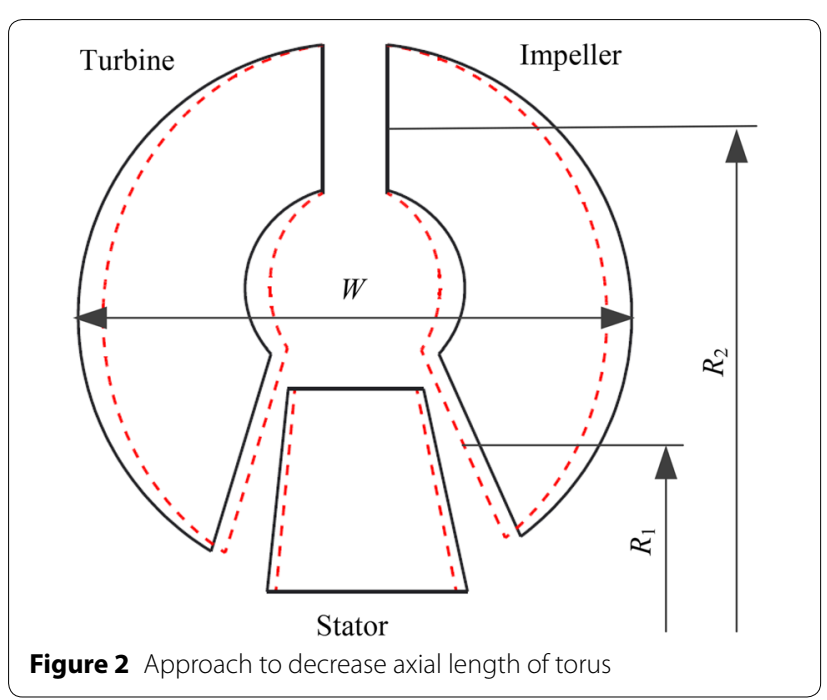

Table 2 Inlet and outlet angles of three elements

\begin{tabular}{lccl}
\hline Parameters & Impeller & Turbine & Stator \\
\hline Inlet angle $\beta_{1}\left({ }^{\circ}\right)$ & 131 & 34 & 97.5 \\
Outlet angle $\beta_{2}\left(^{\circ}\right)$ & 50 & 144 & 21 \\
\hline
\end{tabular}

\section{Flat Torque Converter Design}

\subsection{Computational Method}

To represent the complex geometry of a torque converter and generate the computational mesh in an appropriate way, ICEM and Pro/Engineer respectively, were used. The computational mesh is given in Figure 3 where one blade passage is shown for each element to illustrate the mesh distribution in the computational field when about 81,000 grid cells in total were used. The leakage between the elements and also between an element and the core flow were disregarded. A cyclic boundary condition was imposed on both peripheral boundaries outside a blade passage. A no-slip wall boundary condition was also imposed on all the walls bounding the domain, with a spin applied as necessary. The interfaces between elements have been handled by using the explicit multiple reference frame (MRF) method which allows the problem to be solved in a different rotating reference, instead of a transient moving mesh. The inherent advantage of the MRF approach was the ability to build the computational mesh of each of the rotating components independently. A second-order upwind differencing scheme was utilized and the standard $k-\varepsilon$ model was also used for the turbulence. Steady state simulations were performed for a range of speed ratios from 0.0 to 0.9 while maintaining an impeller speed of $2000 \mathrm{r} / \mathrm{min}$.

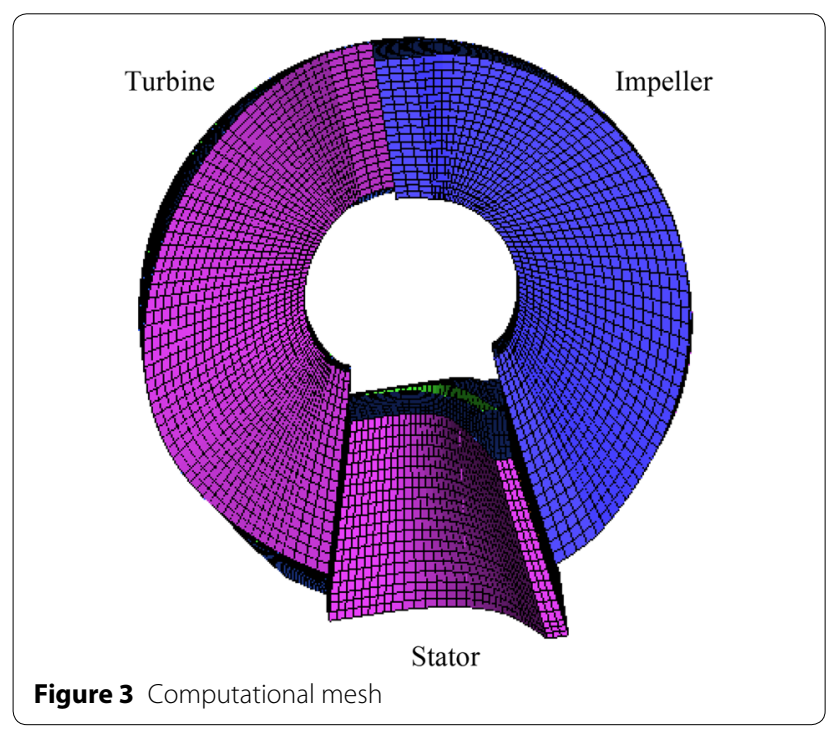




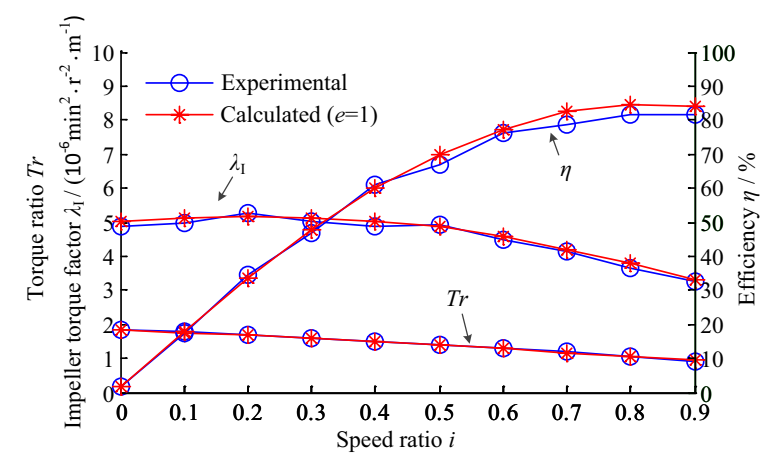

Figure 4 Overall performance of type 1 torque converter

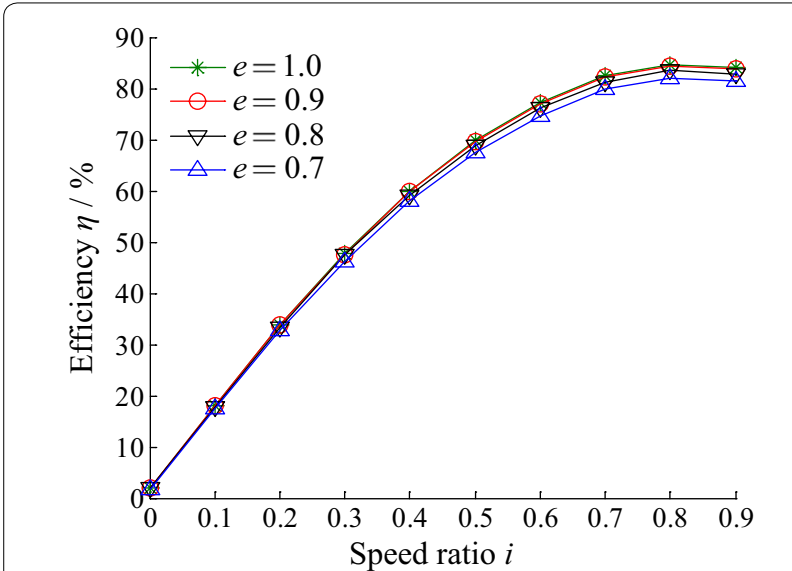

Figure 5 Efficiency of four different types

\subsection{Results and Discussion}

Four torque converters with different flatness ratio were calculated using a CFD code in order to evaluate the change in their overall performance, including efficiency $\eta$, torque ratio $\operatorname{Tr}$ and impeller torque factor $\lambda_{\mathrm{I}}$. The accuracy of the evaluation results was highly dependent on the accuracy of the CFD results. Therefore, it was important to obtain reliable CFD results. Figure 4 compares the measured and calculated overall performance for the type 1 torque converter. As indicated here, the tendencies of the experimental data correlated relatively well with the calculated results, confirming that the computational method is valid in general.

Figure 5 shows the overall efficiencies calculated for all four types of torque converters. As the flatness ratio $e$ decreases, the overall efficiency decreases, which is quite remarkable at high speed ratio. The main cause of this decline in overall efficiency was attributed to a greater loss within the fluid flow channels due to flattening. Figure 6 describes the torque ratio $\operatorname{Tr}$ versus the speed ratio $i$ with four types of torque converters. It is of note that the type $2(e=0.9)$ has nearly the same values with the
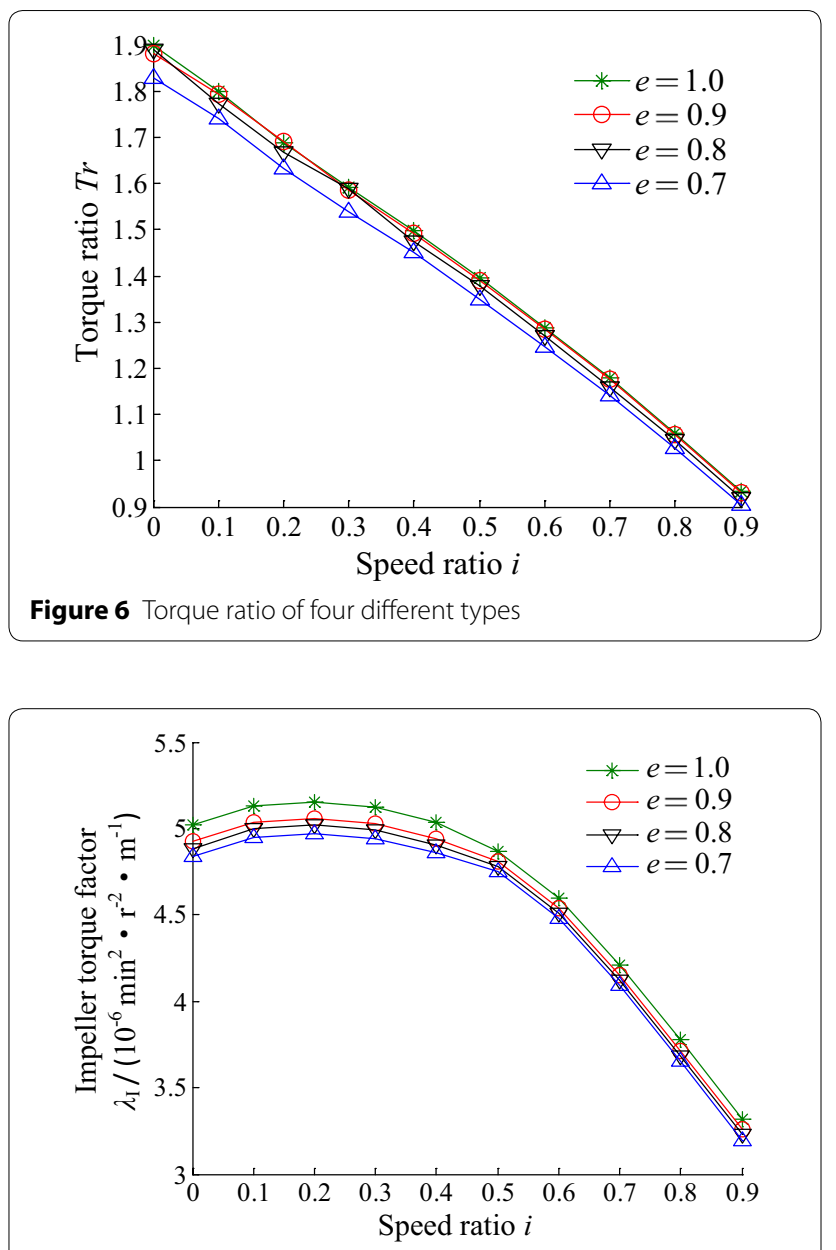

Figure 7 Impeller torque factor of four different types

reference type $(e=1.0)$, and the other types show the lower torque ratio throughout the whole range of speed ratios. Figure 7 illustrates the impeller torque factor comparison among the four types. Among the four types, the type $4(e=0.7)$ shows the lowest value of impeller torque factor $\lambda_{\mathrm{I}}$. When the flatness ratio $e$ decreases, the magnitude of the impeller torque factor $\lambda_{\mathrm{I}}$ tends to decrease especially at low speed ratio. Based on the results in Figures $5,6,7$, it is concluded that the overall performance tends to deteriorate as the flatness ratio $e$ decreases.

\section{Optimal Design of a Flat Torque Converter}

The trend in future automatic-transmission designs is to achieve comparable performance to traditional designs but with reduced mass and in less space. The challenge in torque converter design is to develop a reduced-width torus without sacrificing performance. In this paper, CFD is used to analyze numerous iterations of torque converters to optimize the torus for the allowed space. The type 4 torque converter with flatness ratio $0.158(e=0.7)$ was chosen as the study object. 


\subsection{Sensitivity Analysis of Inlet and Outlet Angles}

Since the blade transmits all of the torque of a torque converter, its design is of utmost importance. In fact, each of the blades would receive working fluid without shock, deflect the flow smoothly throughout the length of blade passage, and discharge the fluid at the optimum angle at all conditions of speed ratio and torque distribution. Unfortunately, it is very difficult to meet optimal requirements. In the present study, a sensitivity analysis was used to investigate the effect of the blade geometric parameters on the torque converter performance characteristics. The main parameters investigated in this paper were inlet and outlet angles of the impeller, turbine, and stator. To improve the design efficiency, a software was developed for generating the blades with various inlet and outlet angles [22]. The blades of type 1 torque converter with inlet and outlet angles shown in Table 2 were chosen as the reference blades in order to compare the performances of the others. Finally, blades of the impeller, turbine, and stator with various inlet and outlet angles $\left(5^{\circ}, 10^{\circ}\right.$, or $15^{\circ}$ below and above the reference value of the parameter) were generated.

Torque converters with different blades were calculated using the above-mentioned computational method in order to evaluate the effect of inlet and outlet angles on their overall performance, including peak efficiency $\eta^{*}$ and stall torque ratio $T r_{0}$. Figure 8 shows the sensitivity of impeller inlet and outlet angles on the performance characteristics of the converter. The impeller inlet angle $\beta_{\mathrm{I}}$ ranges from $115^{\circ}$ to $145^{\circ}$ while the outlet angle $\beta_{\mathrm{I} 2}$ ranges from $35^{\circ}$ to $65^{\circ}$. In the range of $\beta_{\mathrm{I} 1}$, performance $\operatorname{Tr}_{0}$ decreases with increase of angle, whereas $\eta^{*}$ increases. Conversely, the increase of $\beta_{\mathrm{I} 2}$ causes increase of $\operatorname{Tr}_{0}$ and decrease of $\eta^{*}$. Figure 9 provides the sensitivity of turbine inlet and outlet angles on the performance characteristics of the converter. The turbine inlet angle $\beta_{\mathrm{T} 1}$ ranges from $20^{\circ}$ to $55^{\circ}$ while the outlet angle $\beta_{\mathrm{T} 2}$ ranges from $120^{\circ}$ to

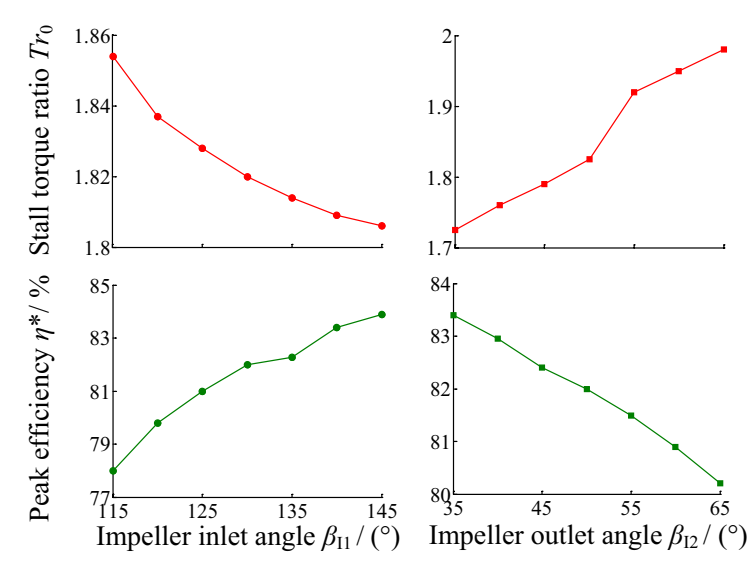

Figure 8 Impeller inlet and outlet angles sensitivity analysis $155^{\circ}$. It is of note that the torque converter with reference blades shows the highest value of $\operatorname{Tr}_{0}$ among simulation cases with different $\beta_{\mathrm{T} 1}$ and highest value of $\eta^{*}$ among simulation cases with different $\beta_{\mathrm{T} 2}$. The simulation case with $\beta_{\mathrm{T} 1}$ five degree lower than the reference blade shows drastically decreases in $\eta^{*}$. It is seen that $\operatorname{Tr}_{0}$ decreases with increase of $\beta_{\mathrm{T} 2}$. Figure 10 illustrates the sensitivity of stator inlet and outlet angles on the performance characteristics of the converter. The stator inlet angle $\beta_{\mathrm{S} 1}$ ranges from $80^{\circ}$ to $115^{\circ}$ while the outlet angle $\beta_{\mathrm{S} 2}$ ranges from $5^{\circ}$ to $40^{\circ}$. Similarly, the simulation case with reference blades shows the highest $T_{0}$ value among cases with different $\beta_{\mathrm{S} 1}$. Performance $\eta^{*}$ increases first and then decreases with increase of $\beta_{\mathrm{S} 1}$. It is found that both performance $\operatorname{Tr}_{0}$ and $\eta^{*}$ decrease with increase of $\beta_{\mathrm{S} 2}$.

Based on the results in Figures 8, 9, 10, it is concluded that the inlet and outlet angles of the impeller, turbine and stator play an important role in determining the performance characteristics of a torque converter including stall torque ratio and peak efficiency. The sensitivity analysis provides useful information of the influence of design parameters individually on the flat torque converter, but not provides information on their combinations effect. Later, a DOE technique would be used to gauge the combination effect of these six dominant parameters.

\subsection{DOE Method}

Design of experiments (DOE) is a collection of mathematical and statistical techniques to reduce the number of experiments in order to find the effect of parameters affecting a response in a process, thereby aiming for a reduction in both costs and time [23-25]. It is also useful to obtain a great deal of information through an action to reduce the number of simulations. The aim is to select some points that the numerical simulations should be investigated and can be adopted for planning, conducting, analyzing, and interpreting controlled tests in order to evaluate the factors that control the value of a parameter or group of parameters. A DOE method sets out configurations (or arrangements) to be conducted using an appropriate orthogonal array; the terminology used in these arrays includes "factors"-an item that is to be varied during the simulations, "level"-the number of times a factor is to be varied during the simulations and "configuration number"- the number of simulations that are required to be run to complete the analysis [26]. For this paper six main geometrical parameters of a torque converter are selected as design variables (factors), which are the inlet and outlet angles mentioned above. For each design parameter, five different values (levels) were assigned. So $25\left(L_{25}\left[5^{6}\right]\right)$ configurations with different combinations were generated for DOE. The original values of the six parameters are listed in Table 2 and the 

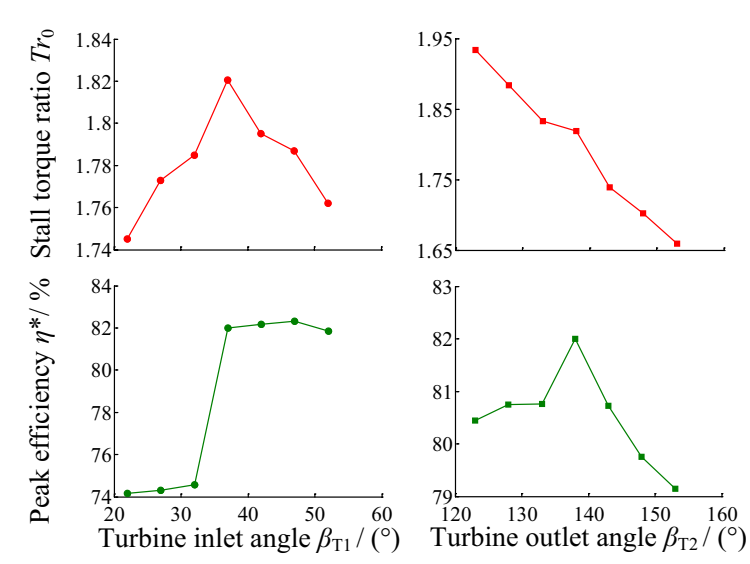

Figure 9 Turbine inlet and outlet angles sensitivity analysis

step values were chosen to be $3^{\circ}$ for each factor. The final configurations for DOE can be constructed as shown in Table 3.

\subsection{Numerical Simulation}

The 25 cases with different blade dimensions were simulated using the above-mentioned method. Stall torque ratio and peak efficiency were selected as the dynamic characteristic and economic characteristic, respectively, to evaluate the performance characteristics of the flat torque converter. The simulation results are also presented in Table 3. It can be seen that among the cases, numbers 14 and 19 have the two best results of stall torque ratio, and number 19 and 15 have the two best results of peak efficiency. It is clear that the maximum stall torque ratio and the maximum peak efficiency can not be obtained at the same time. So, an optimization study is needed to improve the overall performance of the flat torque converter.

\subsection{DOE Post-processing and Optimization}

The processing of the data obtained from DOE could be described as below. Firstly, the 25 cases were grouped by the levels of a factor. Taking factor turbine inlet angle $\beta_{\mathrm{T} 1}$ as example, five groups could be obtained and each of them had the same value (as shown in Table 3). The average value of the stall torque ratio $T r_{0}$ of each group could be calculated as follows:

$$
\begin{aligned}
K_{1} & =\frac{1.7996+1.8055+1.8359+1.8055+1.7852}{5} \\
& =1.80634, \\
K_{2} & =\frac{1.7621+1.7961+1.8014+1.8147+1.8199}{5} \\
& =1.79884,
\end{aligned}
$$

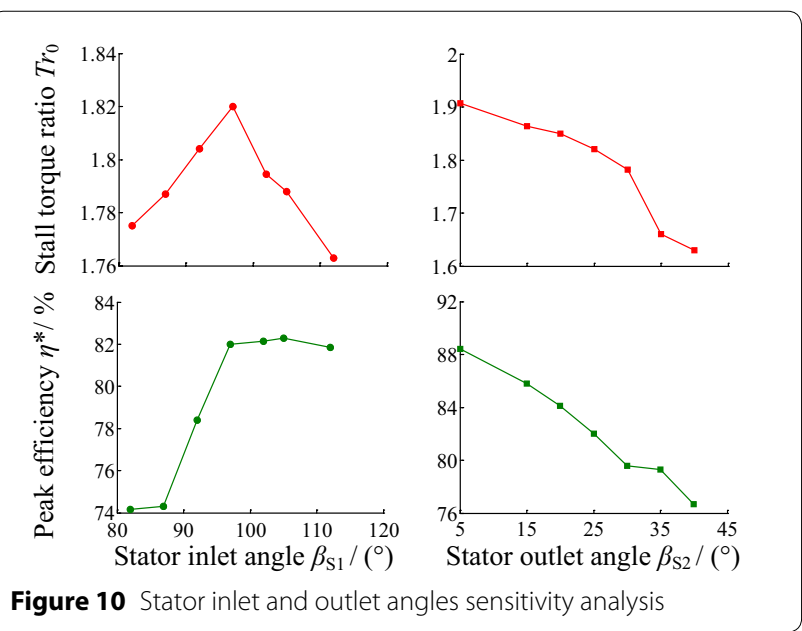

$$
\begin{aligned}
K_{3} & =\frac{1.7699+1.7996+1.8269+1.8455+1.8347}{5} \\
& =1.81532, \\
K_{4} & =\frac{1.7806+1.7982+1.7717+1.8426+1.8364}{5}=1.8059,
\end{aligned}
$$

$$
\begin{aligned}
K_{5} & =\frac{1.7998+1.7516+1.7817+1.7995+1.8106}{5} \\
& =1.78864,
\end{aligned}
$$

To be more clear, the influence levels $K_{1}, K_{2}, K_{3}, K_{4}$, and $K_{5}$ were the average stall torque ratio when turbine inlet angle $\beta_{\mathrm{T} 1}$ equaled $28^{\circ}, 31^{\circ}, 34^{\circ}, 37^{\circ}$, and $40^{\circ}$, respectively. Then, the peak efficiency could be processed by the same method. In addition, range $\mathrm{R}$ was defined as the difference between maximum and minimum values. Finally, the overall DOE analysis data was calculated and shown in Table 4.

The range $\mathrm{R}$ reflects the influence level of each geometrical parameter on the hydrodynamic characteristics of a torque converter. The contribution value $C$ was defined as the percentage of the $\mathrm{R}$ value of a specific factor to the total $R$ values of all the factors. A factor with larger $\mathrm{R}$ would have more influence on torque converter performance indicators, and was considered as an important factor during converter design. While factors with small range value $\mathrm{R}$ would be considered as less important factors during design procedure. It could be found in Table 4 that, parameters turbine outlet angle $\beta_{\mathrm{T} 2}$ and stator outlet angle $\beta_{\mathrm{S} 2}$ are the two most important factors. To be more precise, the descending sort of range $\mathrm{R}$ is $\beta_{\mathrm{T} 2}>\beta_{\mathrm{S} 2}>\beta_{\mathrm{T} 1}>\beta_{\mathrm{S} 1}>\beta_{\mathrm{I} 2}>\beta_{\mathrm{I} 1}$ for stall torque ratio, and $\beta_{\mathrm{T} 2}>\beta_{\mathrm{S} 2}>\beta_{\mathrm{T} 1}>\beta_{\mathrm{I} 2}>\beta_{\mathrm{I} 1}>\beta_{\mathrm{S} 1}$ for peak efficiency. Therefore, more focuses are needed on the 
Table 3 Configurations and simulation results in DOE

\begin{tabular}{|c|c|c|c|c|c|c|c|c|}
\hline \multirow[t]{2}{*}{ Case number } & \multicolumn{6}{|l|}{ Factors } & \multicolumn{2}{|l|}{ Responses } \\
\hline & $\begin{array}{l}\text { Turbine inlet } \\
\text { angle } \beta_{\mathrm{T} 1}\left({ }^{\circ}\right)\end{array}$ & $\begin{array}{l}\text { Turbine outlet } \\
\text { angle } \beta_{\mathrm{T} 2}\left({ }^{\circ}\right)\end{array}$ & $\begin{array}{l}\text { Impeller inlet } \\
\text { angle } \beta_{11}\left({ }^{\circ}\right)\end{array}$ & $\begin{array}{l}\text { Impeller outlet } \\
\text { angle } \beta_{12}\left({ }^{\circ}\right)\end{array}$ & $\begin{array}{l}\text { Stator inlet } \\
\text { angle } \beta_{\mathrm{S} 1}\left({ }^{\circ}\right)\end{array}$ & $\begin{array}{l}\text { Stator outlet } \\
\text { angle } \beta_{\mathrm{S} 2}\left({ }^{\circ}\right)\end{array}$ & $\begin{array}{l}\text { Stall torque } \\
\text { ratio } T r_{0}\end{array}$ & $\begin{array}{l}\text { Peak } \\
\text { efficiency } \\
\eta^{*}(\%)\end{array}$ \\
\hline 1 & 28 & 138 & 125 & 44 & 91.5 & 15 & 1.7996 & 80.96 \\
\hline 2 & 28 & 141 & 128 & 47 & 94.5 & 18 & 1.8055 & 81.65 \\
\hline 3 & 28 & 144 & 131 & 50 & 97.5 & 21 & 1.8359 & 82.98 \\
\hline 4 & 28 & 147 & 134 & 53 & 100.5 & 24 & 1.8055 & 81.23 \\
\hline 5 & 28 & 150 & 137 & 56 & 103.5 & 27 & 1.7852 & 80.36 \\
\hline 6 & 31 & 138 & 128 & 50 & 100.5 & 27 & 1.7621 & 78.34 \\
\hline 7 & 31 & 141 & 131 & 53 & 103.5 & 15 & 1.7961 & 79.17 \\
\hline 8 & 31 & 144 & 134 & 56 & 91.5 & 18 & 1.8014 & 80.29 \\
\hline 9 & 31 & 147 & 137 & 44 & 94.5 & 21 & 1.8147 & 80.37 \\
\hline 10 & 31 & 150 & 125 & 47 & 97.5 & 24 & 1.8199 & 80.11 \\
\hline 11 & 34 & 138 & 131 & 56 & 94.5 & 24 & 1.7699 & 77.19 \\
\hline 12 & 34 & 141 & 134 & 44 & 97.5 & 27 & 1.7996 & 79.82 \\
\hline 13 & 34 & 144 & 137 & 47 & 100.5 & 15 & 1.8269 & 82.36 \\
\hline 14 & 34 & 147 & 125 & 50 & 103.5 & 18 & 1.8455 & 82.76 \\
\hline 15 & 34 & 150 & 128 & 53 & 91.5 & 21 & 1.8347 & 83.21 \\
\hline 16 & 37 & 138 & 134 & 47 & 103.5 & 21 & 1.7806 & 79.24 \\
\hline 17 & 37 & 141 & 137 & 50 & 91.5 & 24 & 1.7982 & 81.25 \\
\hline 18 & 37 & 144 & 125 & 53 & 94.5 & 27 & 1.7717 & 79.53 \\
\hline 19 & 37 & 147 & 128 & 56 & 97.5 & 15 & 1.8426 & 83.24 \\
\hline 20 & 37 & 150 & 131 & 44 & 100.5 & 18 & 1.8364 & 81.71 \\
\hline 21 & 40 & 138 & 137 & 53 & 97.5 & 18 & 1.7998 & 80.21 \\
\hline 22 & 40 & 141 & 125 & 56 & 100.5 & 21 & 1.7516 & 77.59 \\
\hline 23 & 40 & 144 & 128 & 44 & 103.5 & 24 & 1.7817 & 79.24 \\
\hline 24 & 40 & 147 & 131 & 47 & 91.5 & 27 & 1.7995 & 78.47 \\
\hline 25 & 40 & 150 & 134 & 50 & 94.5 & 15 & 1.8106 & 81.56 \\
\hline
\end{tabular}

Table 4 Overall DOE analysis data

\begin{tabular}{|c|c|c|c|c|c|c|c|}
\hline Indicator & $\begin{array}{l}\text { Influence } \\
\text { level }\end{array}$ & $\begin{array}{l}\text { Turbine inlet } \\
\text { angle } \beta_{\mathrm{T} 1}\end{array}$ & $\begin{array}{l}\text { Turbine outlet } \\
\text { angle } \beta_{\mathrm{T} 2}\end{array}$ & $\begin{array}{l}\text { Impeller inlet } \\
\text { angle } \beta_{11}\end{array}$ & $\begin{array}{l}\text { Impeller outlet } \\
\text { angle } \beta_{12}\end{array}$ & $\begin{array}{l}\text { Stator inlet } \\
\text { angle } \beta_{\mathrm{S} 1}\end{array}$ & $\begin{array}{l}\text { Stator } \\
\text { outlet } \\
\text { angle } \beta_{\mathrm{S} 2}\end{array}$ \\
\hline \multirow[t]{7}{*}{ Stall torque ratio $T r_{0}$} & $K_{1}$ & 1.80634 & 1.78240 & 1.79766 & 1.80640 & 1.80668 & 1.81516 \\
\hline & $K_{2}$ & 1.79884 & 1.79020 & 1.80532 & 1.80648 & 1.79448 & 1.81772 \\
\hline & $K_{3}$ & 1.81532 & 1.80352 & 1.80756 & 1.81046 & 1.81956 & 1.80350 \\
\hline & $K_{4}$ & 1.80590 & 1.82156 & 1.79954 & 1.80156 & 1.79650 & 1.79504 \\
\hline & $K_{5}$ & 1.78864 & 1.81736 & 1.80496 & 1.79014 & 1.79782 & 1.78362 \\
\hline & $\mathrm{R}$ & 0.02668 & 0.03916 & 0.00990 & 0.02032 & 0.02508 & 0.03410 \\
\hline & C & $17 \%$ & $25 \%$ & $7 \%$ & $13 \%$ & $16 \%$ & $22 \%$ \\
\hline \multirow[t]{7}{*}{ Peak efficiency $\eta^{*}(\%)$} & $K_{1}$ & 81.436 & 79.188 & 80.190 & 80.420 & 80.836 & 81.458 \\
\hline & $K_{2}$ & 79.656 & 79.896 & 81.136 & 80.366 & 80.060 & 81.324 \\
\hline & $K_{3}$ & 81.068 & 80.880 & 79.904 & 81.378 & 81.272 & 80.678 \\
\hline & $K_{4}$ & 80.994 & 81.214 & 80.028 & 80.670 & 80.246 & 79.804 \\
\hline & $K_{5}$ & 79.014 & 81.390 & 80.910 & 79.734 & 80.154 & 79.304 \\
\hline & $\mathrm{R}$ & 2.022 & 2.202 & 1.232 & 1.644 & 1.212 & 2.154 \\
\hline & C & $19 \%$ & $21 \%$ & $12 \%$ & $16 \%$ & $12 \%$ & $20 \%$ \\
\hline
\end{tabular}


optimization of turbine outlet angle and stator outlet angle in the design phase, in order to achieve better performance of the flat torque converter. It should be noted that the results may have some difference with the conclusions studied before. This is possible caused by the level selection of design parameters. In the present study, the desirability function was used to carry out the optimization [27]. The optimization results depend on the response weights of stall torque ratio and peak efficiency. In this study, optimization analysis was performed provided that the stall torque ratio and peak efficiency had the same response weight. The results show that case 19 , that is, $37^{\circ}$ for $\beta_{\mathrm{T} 1}, 147^{\circ}$ for $\beta_{\mathrm{T} 2}, 128^{\circ}$ for $\beta_{\mathrm{I} 1}, 56^{\circ}$ for $\beta_{\mathrm{I} 2}, 97.5^{\circ}$ for $\beta_{\mathrm{S} 1}$, and $15^{\circ}$ for $\beta_{\mathrm{S} 2}$, have the best overall performance of the flat torque converter. Compared to the conventional product $(e=1.0)$, the flat torque converter with flatness ratio $0.158(e=0.7)$ is developed that reduce the width of the torus by about $20 \%$. The axial length of the optimal flat torque converter and its weight have been substantially reduced while the values of stall torque ratio and peak efficiency are only decreased by $0.4 \%$ and $1.7 \%$, respectively.

\section{Conclusions}

1. DOE method based on CFD technique is applied to obtain an optimized design of a flat torque converter geometry. To this end, 25 cases with different inlet and outlet angles of impeller, turbine, and stator are designed, constructed and simulated. The main advantage of DOE is its ability to consider the combination effect of design parameters on performance, as it is not limited to traditional one-factor-at-a-time approach.

2. The analysis of the DOE array identified the dominant geometrical influences on the performance of the flat torque converter. In general, the turbine outlet angle and stator outlet angle are the two strongest influences on the converter performance characteristics, including stall torque ratio and peak efficiency.

3. Based on the calculation results in DOE, desirability function approach is employed to optimize the flat torque converter geometry. It should be noted that the maximum values of stall torque ratio and peak efficiency can not be obtained at the same time. Finally, the best design configuration is achieved at case 19 , that is, $37^{\circ}$ for turbine inlet angle, $147^{\circ}$ for turbine outlet angle, $128^{\circ}$ for impeller inlet angle, $56^{\circ}$ for impeller outlet angle, $97.5^{\circ}$ for stator inlet angle, and $15^{\circ}$ for stator outlet angle. The optimization method first used in performance improvement of flat torque converters can provide fundamental guidelines for designers.
Authors' Contributions

G-QW and JC were in charge of the whole trial; JC wrote the manuscript; JC and W-JZ assisted with sampling and laboratory analyses. All authors read and approved the final manuscript.

\section{Author details}

1 School of Automotive Studies, Tongji University, Shanghai 201804, China.

${ }^{2}$ Institute of Industrial Science, The University of Tokyo, Tokyo 153-8505, Japan.

\section{Authors' Information}

Guang-Qiang Wu, born in 1965, is currently a professor and a PhD candidate supervisor at School of Automotive Studies, Tongji University, China and Institute of Industrial Science, the University of Tokyo, Japan. He received his PhD degree from Jilin University, China, in 1994. His main research interests include advanced design theory and method of the automobile.

Jie Chen, born in 1988, is currently a PhD candidate at School of Automotive Studies, Tongji University, China. His main research interests include flow simulation, modification and optimal design theory for the torque converter Wen-Jie Zhu, born in 1989, is currently a master candidate at School of Automotive Studies, Tongji University, China. His research interests include flow simulation, modification and optimum design theory for the torque converter.

\section{Competing Interests}

The authors declare that they have no competing interests.

Funding

Supported by National Natural Science Foundation of China (Grant No. 51575393).

\section{Publisher's Note}

Springer Nature remains neutral with regard to jurisdictional claims in published maps and institutional affiliations.

Received: 21 July 2016 Accepted: 2 Auqust 2018

Published online: 10 August 2018

\section{References}

[1] B Zhao, Y Wang, H Chen, et al. Hydraulic optimization of a double-channel pump's impeller based on multi-objective genetic algorithm. Chinese Journal of Mechanical Engineering, 2015, 28(3): 634-640.

[2] D Li, R Gong, HWang, et al. Entropy production analysis for hump characteristics of a pump turbine model. Chinese Journal of Mechanical Engineering, 2014: 1-10

[3] M H Shojaeefard, M Tahani, M B Ehghaghi, et al. Numerical study of the effects of some geometric characteristics of a centrifugal pump impeller that pumps a viscous fluid. Computers \& Fluids, 2012, 60: 61-70.

[4] L Tan, B Zhu, S Cao, et al. Influence of blade wrap angle on centrifugal pump performance by numerical and experimental study. Chinese Journal of Mechanical Engineering, 2014, 27(1): 171-177.

[5] G Q Wu, P Yan. System for torque converter design and analysis based on CAD/CFD integrated platform. Chinese Journal of Mechanical Engineering, 2008, 21(4): 35-39.

[6] D Yu, V Korivi, P Attibele, et al. Torque converter CFD engineering Part I: torque ratio and $\mathrm{K}$ factor improvement through stator modifications. SAE Transmission and Driveline Systems Symposium, Detroit, USA, March 4, 2002: 2002-01-0883.

[7] M Kubo, E Ejiri. A loss analysis design approach to improving torque converter performance. SAE Transmission and Driveline Systems Symposium, Detroit, USA, February 25, 1998: 981100

[8] S Shin, KJ Kim, D J Kim, et al. The effect of reactor blade geometry on the performance of an automotive torque converter. SAE Transmission and Driveline Systems Symposium, Detroit, USA, March 4, 2002: 2002-01-0885.

[9] S Shin, B C Lee, J H Hong, et al. Performance improvement using a slotted stator of an automotive torque converter. SAE Transmission and Driveline Systems Symposium, Detroit, USA, March 4, 2003: 2003-01-0247. 
[10] K Song, K Kim, J Park, et al. Development of the integrated process for torque converter design and analysis. SAE Technical paper, Detroit, USA, April 15, 2008: 2008-01-0785.

[11] E Ejiri, M Kubo. Influence of the flatness ratio of an automotive torque converter on hydrodynamic performance. Journal of Fluids Engineering, 1999, 121(3): 614-620.

[12] G Kim, J Jang. Effects of stator shapes on hydraulic performances of an automotive torque converter with a squashed torus. SAE Transmission and Driveline Systems Symposium, Detroit, USA, March 4, 2002: 2002-01-0886.

[13] T Ochi, H Takeichi, H Kimura, et al. Development of a super-flat torque converter for the new Toyota FWD 6-speed automatic transaxle. SAE Transmission and Driveline Systems Symposium, Detroit, USA, March 4, 2006: 2006-01-0149.

[14] T Kietlinski, M Fingerman. 248 mm elliptical torque converter from daimlerchrysler corporation. SAE Transmission and Driveline Systems Symposium, Detroit, USA, March 4, 2007: 2007-01-0241.

[15] T Usui, T Okaji, T Muramatsu, et al. Development of a compact ultra-flat torque converter equipped with a high-performance damper. SAE International Journal of Engines, Detroit, USA, April 22, 2015, 8(2015-01-1088): 1374-1378.

[16] H Abe, M Tsuruoka, A Muto, et al. Development of super ultra flat torque converter with multi plate lock-up clutch. SAE International Journal of Engines, Detroit, USA, April 21, 2009, 2(2009-01-0141): 48-55.

[17] Q D Yan, C Liu, W Wei. Numerical simulation of the flow field of a flat torque converter. Journal of Beijing Institute of Technology, 2012, 21(3): 309-314.

[18] C B Liu, W X Ma, X L Zhu, et al. Design method of flat hydrodynamic torque converter for passenger car based on elliptic torus. Journal of Jilin University (Engineering and Technology Edition), 2010, 40(4): 1039-1043, 2010. (in Chinese)

[19] J Park, H Cha, S Song, et al. A numerical study of a methane-fueled gas engine generator with addition of hydrogen using cycle simulation and DOE method. International Journal of Hydrogen Energy, 2011, 36(8): 5153-5162.

[20] M Hatami, M C M Cuijpers, M D Boot. Experimental optimization of the vanes geometry for a variable geometry turbocharger (VGT) using a design of experiment (DoE) approach. Energy Conversion and Management, 2015, 106: 1057-1070

[21] H Taghavifar, S Jafarmadar, H Taghavifar, et al. Application of DoE evaluation to introduce the optimum injection strategy-chamber geometry of diesel engine using surrogate epsilon-SVR. Applied Thermal Engineering, 2016, 106: 56-66

[22] L J Wang, G J Wu, G Hwan. Design strategy for modification of torque converters based on variation law of blade angle. Journal of Tongji University (Natural Science), 2011, 39(11):1673-1679. (in Chinese)

[23] M Hatami, M Jafaryar, D D Ganji, et al. Optimization of finned-tube heat exchangers for diesel exhaust waste heat recovery using CFD and CCD techniques. International Communications in Heat and Mass Transfer, 2014, 57: 254-263.

[24] M Hatami, D D Ganji, M Gorji-Bandpy. Experimental and thermodynamical analyses of the diesel exhaust vortex generator heat exchanger for optimizing its operating condition. Applied Thermal Engineering, 2015, 75: 580-591.

[25] M Hatami, D D Ganji, M Gorji-Bandpy. Experimental and numerical analysis of the optimized finned-tube heat exchanger for OM314 diesel exhaust energy recovery. Energy Conversion and Management, 2015, 97 : 26-41.

[26] R Spence, J Amaral-Teixeira. A CFD parametric study of geometrical variations on the pressure pulsations and performance characteristics of a centrifugal pump. Computers \& Fluids, 2009, 38(6): 1243-1257.

[27] A Sagbas. Analysis and optimization of surface roughness in the ball burnishing process using response surface methodology and desirability function. Advances in Engineering Software, 2011, 42(11): 992-998.

\section{Submit your manuscript to a SpringerOpen ${ }^{\circ}$ journal and benefit from:}

- Convenient online submission

- Rigorous peer review

- Open access: articles freely available online

- High visibility within the field

- Retaining the copyright to your article

Submit your next manuscript at springeropen.com 